ZDRAVKO PERAN, Ph.D.

E-mail: zdravko.peran2@si.htnet.hr

University of Split,

University Department of Forensic Science Split

Ruđera Boškovića 31/IV, 21000 Split, Croatia
Transport Technology

Preliminary Communication

Submitted: Feb. 19, 2015

Approved: Feb. 2, 2016.

\title{
DYNAMIC FORCES BETWEEN THE RAILS AND THE WHEELS OF RAILWAY VEHICLE
}

\begin{abstract}
The process of acquisition of the measured dynamic values of forces between the rails and the wheels on the real measurement train and the train tracks. The conversion of the measured values into the matrices and vectors enables numerous exact qualitative and quantitative studies of the dynamic phenomena behaviour. The paper shows the possibilities of using MATLAB computer tool. All the commands in the software are given and explained. Calculating of the empirical, normal and cumulative distribution on an example of the lateral force is given in detail. The new software is exactly verified mathematically and qualified for any further use. The developed software is the tool for the development of other two phases: software for the exact automatic evaluation of the maximum values of the dynamic values and software for the automatic approval of vehicles and railway due to the driving safety, loading tracks and driving comfort compared to the limited values regarding UI C CODE 518.
\end{abstract}

\section{KEY WORDS}

measurement train; lateral and vertical forces; UIC CODE 518; driving safety; empirical, normal and cumulative distribution; software verification;

\section{INTRODUCTION}

UIC CODE 518 [1] is the most significant regulation and assistance to the experts regarding the evaluation and approval of the new vehicles and railways or during the revision of the existing means of rail transport, which relate to the safety driving, railway weight and ride quality.

Part of these regulations, which are based on the use of methods of statistical mathematics regarding the processing of the measurement results, are still not applicable in the European practice, since it is not easy to perform the prescribed measurements as well as the prescribed results analysis. Serious vehicle manufacturers are well equipped with the measurement train and the instruments, but the measurement result analysis is carried out without the statistical processing regulated in the UIC CODE 518.
The author of this thesis in his original approach, research and work has developed the complete software for the exact automatic statistical analysis of the measurement data with the use of the MATLAB computer tool. This thesis provides an overview of the first phase of the software, more precisely, data acquisition, empirical, normal and cumulative distribution, followed by other phases of the developed software, i.e. software for the exact automatic evaluation of the maximal values of the dynamic size and the automatic approval vehicles and railways software regarding the driving safety, load line and driving comfort compared to the regulated limit values from the UIC CODE 518. Other two software phases are still in manuscript. It is strongly believed that the application software as an official addition to the UIC CODE 518 will be accepted.

At this stage, the process of acquisition of measuring the size of the dynamic force between the rail and the wheel of the actual measurement train and the track is therefore provided, and later the measured sizes are converted into the matrices and vectors. A detailed survey of the calculation of the empirical, normal and cumulative distribution has been provided, given the example of the lateral force $Y 11$. The aforementioned process will be applied later in the exact mathematical evaluation of the maximum values of the measured sizes as well as the automatic comparison of the calculated results with the limits according to the UIC CODE 518.

This phase of the application software has been completed, mathematically and exactly verified and qualified for any further application.

\section{ACQUISITION AND DATA MEASUREMENTS PREPARATION FOR THE ANALYSIS}

Dynamic size measurements regarding the vehicle railway system with the test tilting train Pendolino ETR-470-ZERO on the Zagreb-Rijeka railway line were conducted in July 1996, and the development of the application software was carried out later on the basis of the data given by the Fiat Ferroviaria company and 
submitted to numerous disks. It is not known whether some similar software for the exact qualitative and quantitative analysis of actual measurement results via MATLAB has been developed anywhere in Europe; however, there are no such published theses.

The actual measurement data used for the development of the overall application software on the measurement train for six consecutive measurement sequences of the Moravice-Ogulin railway was isolated: for the direction railway, for the right crossing, for the right full arc, for the crossing at the exit from the full right arc, for the crossing into the left arc and for the full left arc. The sample sizes for all test sections are about 150 elements, or rows. If the size of the matrix needs to be equalized, there is a familiar algorithm and software for the procedure, but, if necessary, it can be given to the application software user.

The measured and calculated sizes from the measurement train consist of an imposing set of $35 \mathrm{dy}-$ namic sizes. All sizes are observed as matrices and vectors in the syntax and the features of the used MAT$\mathrm{LAB}$ programming tool which are used to calculate and present the results.

For instance, lateral force on the right wheel of the first axle according to Table 1 is the $Y 11$ vector, and on the left wheel it is the $Y 12$ vector. The matrix of the measured values on the first test section is MMs1.

It is important to mention that out of the 19 measured values for the part of the Moravice-Ogulin railway line according to 3.2 of the UIC 518 instructions in the first phase of the software development only the forces between the wheel and the rail on the front axle Y11, Y12, Q11 and Q12 were analysed as examples.

Out of 35 measured dynamic sizes, the major part is used by the manufacturer of the tilting train for their needs.

The data charts are made out of the measurement data. Furthermore, by putting the parts of the chart in the square bracket and assigning the names, the matrices are made. Data matrices for each railway section are saved as files mmsn.m. An example of the part of the matrix of MMs data for the first railway section is input in the computer file mms1.m., which looks as follows in the abbreviated form, because the entire matrix requires a lot of space.

$\%$ mms $1 . m$

$\%$ measured values Moravice - Ogulin

MMs $=\left[\begin{array}{llllll}1 & 562.99999 & 0.40001 & -12.111 & 14.229 & -7.137\end{array}\right.$

$\begin{array}{llllll}7.137 & 63.698 & 63.804 & 61.477 & 64.989 & 1.484\end{array}$

$\begin{array}{lllllll}-0.294 & -0.193 & 0.216 & -0.114 & 0.104 & 54.17 & 0.087\end{array}$ $\begin{array}{llllll}2 & 562.99992 & 0.40008 & -12.084 & 14.410 & -7.036\end{array}$

$\begin{array}{llllll}7.184 & 63.867 & 63.723 & 61.408 & 64.886 & 1.467\end{array}$

$\begin{array}{lllllll}-0.253 & -0.194 & 0.216 & -0.114 & 0.105 & 54.10 & 0.087\end{array}$

...];

The given data in rows and columns for each parameter can be seen in Section 3.1 in the software form in the fully completed matrix mms6.m. for the full arc.

In further analysis, the data matrix for the 6th test section in the railway arc is used, not as the aforementioned first section in the direction of the railway. All six data matrices will be used in other parts of the complete application software.

By using amm.m file, the MMs matrix is reduced to 151 rows and 15 columns:

mms6

MMs=MMs(:,1:15);

\section{NEW POSSIBILITIES OF THE MEASUREMENT DATA ANALYSIS}

The measured forces of the railway section are easily extracted from the MMs matrix force and can be seen through their qualitative and quantitative numerical and graphical displays, as well as through their interrelations. This analysis will consider:

- MMs martix force,

- Y11, Y12 lateral forces,

- Q11, Q12 vertical forces,

- the relationship between the lateral and vertical forces $Y 11 / Q 11$.

\subsection{MMs matrix force}

The measured sizes are distinguished by the columns from the data matrix and are defined as variables - vectors. Therefore, they become available for any operation, calculation and all graphic presentations. Through graphic displays, various sizes are easily understood and their behaviour is easily monitored. Moreover, various qualitative and quantitative analyses, comparisons and conclusions can be carried out and the behaviour of the overall vehicle-railway system can be observed.

In order to achieve automatism in the implementation of the analysis procedure, the files analysis 1.m, amm.m and the additional ffti.1.m $u$ file in MATLAB were made and tested.

The application software starts with the command to call data file mms.6.m, which is the test railway

Table 1 - Tags and descriptions of the measured values

\begin{tabular}{||c|c||}
\hline Symbols & Description \\
\hline \hline Y 11 & Lateral force between the rail and the right wheel of the first axle \\
\hline Y 12 & Lateral force between the rail and the left wheel of the first axle \\
Q 11 & Vertical force between the rail and the right wheel of the 1st axle \\
\hline Q 12 & Vertical force of the rail and the left wheel of the 1st axle \\
\hline
\end{tabular}


section, with MMs matrix, followed by the command global MEV SDE N I, which serves the ffti.1.m file. Columns of matrix data as vectors are obtained by using amm.m file, and become available for arithmetic and graphic operations, which can be seen from the list of vector route in $\mathrm{km}$, to the velocity vector $v$.

$\%$ measurement results analysis

$\%$ analysis1.m

\section{global MEV SDE N I}

mms6

keyboard

amm

km=MMs(:,1); Y11=MMs(:,2); Y12=MMs(:,3); Y21=MMs(:,4); Y22=MMs(:,5); Q11=MMs(:,6); Q12=MMs(:,7); Q21=MMs(:,8); Q22=MMs(:,9); SuY1=MMs(:,10); SuY2=MMs(:,11);

Y_Q11=MMs(:,12); Y_Q12=MMs(:,13);

ay=MMs(:,14); v=MMs(:,15);

keyboard

The columns of the matrices are $m$ vectors $Y 11$, Y12, Y21, Y22, Q11, Q22, SuY1, SuY2, Y_Q11, Y_Q12, ay, $v$; therefore, 15 vectors, which will be studied in two-phase application software.

The matrix data can be graphically presented, but without the $\mathrm{km}$ vector, which is bigger than other vectors for one order of magnitude. The command for this overview is: MMs MMs=(:, 1:15);

And the display can be seen in Figure 1 where only lateral forces $\mathrm{Y} 11$ and $\mathrm{Y} 12$ are specially marked for the clarity of the image, in order to be compared with the images that follow. A detailed analysis of these vectors follows below.

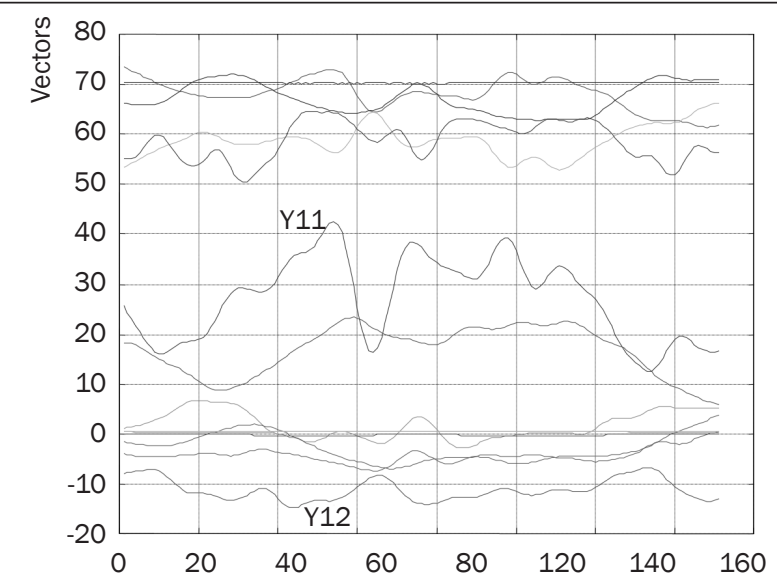

The number of elements in the sample

Figure 1 - Vectors of the 6th test railway section

\subsection{Lateral forces $Y 11$ and $Y 12$}

Graphic qualitative and quantitative representations of lateral forces in the arc of the railway on the first podium and first vehicular composition in the left arc are obtained in Figure 2: plot[km, Y11,km,Y12],grid .

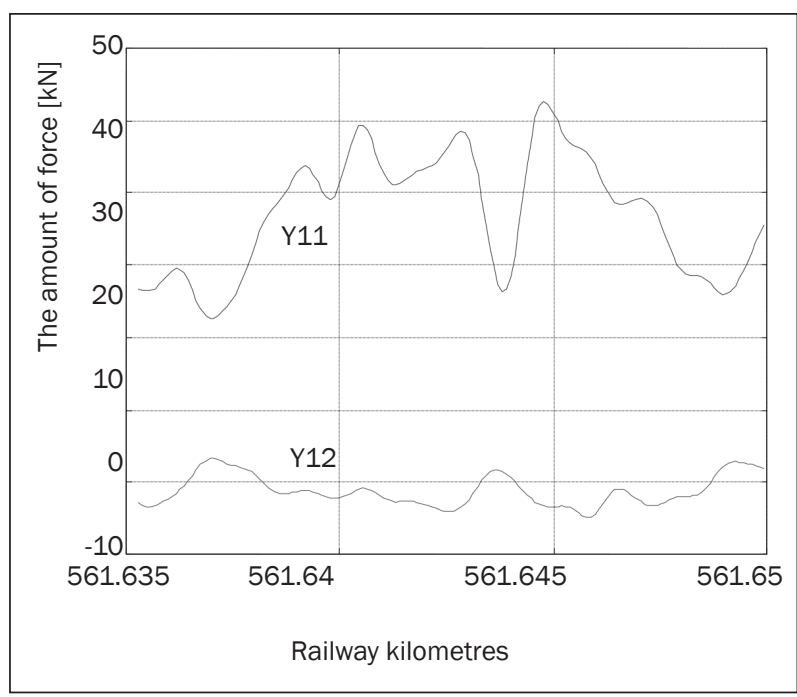

Figure 2 - Lateral forces Y11 and Y12 on the front axle in the railway arc

Lateral force $Y 11$ is measured on the right wheel of the first axle of the measurement train and that is the force that compresses the outer rail to the wheel in the railway arc. Lateral force $\mathrm{Y} 12$ is smaller and negative as well. It is the force of friction between the inner rail in the arc and the wheel and it pulls the wheel; therefore, it is negative. Both forces are quite variable, even the oscillating characteristics are shown.

\subsection{Vertical forces $Q 11$ and $Q 12$}

The command for drawing vertical forces on the 6th railway section in the arc is: plot $(\mathrm{km}, \mathrm{Q} 11, \mathrm{~km}, \mathrm{Q} 12)$, grid and the result can be seen in Figure 3.

Vertical forces $Q 11$ and $Q 12$ in this picture are correlated with lateral forces $Y 11$ and $Y 12$. Force Q11 on the right wheel of the first axle is expected to be higher than the vertical force of the inner rails on the left wheel.

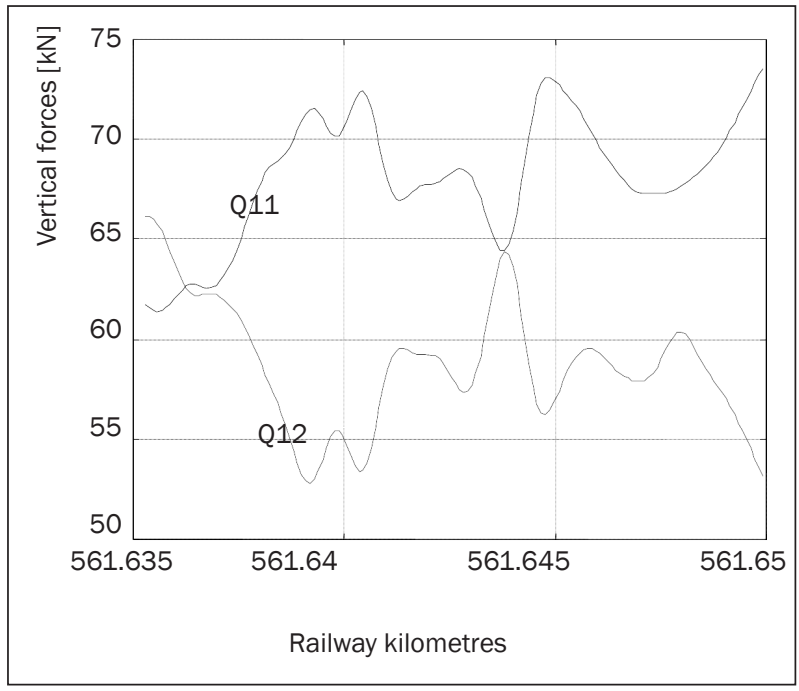

Figure 3 - Vertical forces Q11 and Q12 on the first axle in the railway arc 


\section{$3.4 \mathrm{Y} / \mathrm{Q}$ relation}

As an example of the possible analysis, the $Y / Q$ relation is provided, which will be analysed thoroughly in other software phases. The relation or the quotient between lateral force $Y$ and vertical force $Q$ on the wheels of the first axle of the vehicle, i.e. quotients $Y 11 / Y 12$ and Q11/Q12 are the most important sizes of safety driving.

This size is obtained by measuring, i.e. calculating during measuring. In addition to ten times of the quotient force $Y 11 / Q 11$, the corresponding lateral force $Y 11$ as well as vertical force Q11 is seen in Figure 4.

The command to display these forces and its relation is: $\operatorname{plot}(\mathrm{km}, \mathrm{Y} 11, \mathrm{~km}, \mathrm{Q} 11, \mathrm{~km}, 10 * \mathrm{Y} 11 / \mathrm{Q} 11)$, grid .

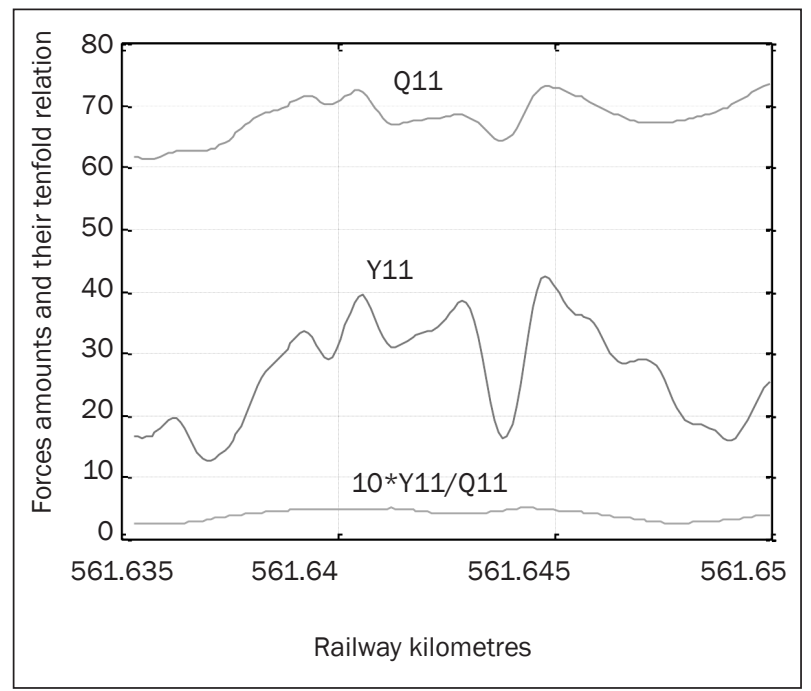

Figure 4 - Lateral and normal forces and their tenfold relation

The highest value of the quotient of $Y 11 / Q 11$ is: $\max$ $(\max (\mathrm{Y} 11) / \max (\mathrm{Q} 11))=0.5790$ which is less than 0.85 as the limit value for this size according to the UIC 518 instruction.

\section{EMPIRICAL AND NORMAL DISTRIBUTION OF MEASURED VALUES}

Firstly, it was necessary to give an overview of a part of the general procedure of statistical data processing, i.e. the empirical, normal and cumulative distribution calculation applied to the analysis of the real data measurements on the measurement train. This part of the procedure will be used intensively later in the second and the third phase of development and presentation of the application software.

To illustrate the process of calculating the empirical, normal and cumulative distribution, the measured value $Y 11$, which is already processed and known, is selected.

As already stated, the measured value $Y 11$, or vector $Y 11$ is prepared for the statistical analysis, collec- tion of 151 individual numerical values. The statistical analysis was obtained on this pattern. The minimum pattern size is determined by the requirement that the pattern is representative for the statistical analysis, which means that there is a sufficient number of elements, which represent a completely random variable.

Statistical analysis is done in three main steps, as follows:

- empirical distribution calculation,

- normal distribution calculation,

- cumulative distribution calculation and verification of the conducted procedure.

\subsection{Empirical distribution calculation}

The total number of elements in the pattern (code $N$ ) is arranged in the spreading area of the pattern elements, and is limited to the minimum and maximum value of the elements. The area is divided into classes (here the number of class 10 is given by software) of equal width (width I). The procedure of conducting the empirical distribution is generally known, and in this case, includes:

- Calculating and drawing a histogram of force Y11,

- Calculating the mean of the pattern MEV,

- Calculating the number of elements $N$ in the pattern,

- Calculating the width of class I,

- Identifying the minimum value in the pattern MIN,

- Searching the maximum value in the pattern MAX,

- Drawing a histogram of the empirical distribution.

The histogram of force $Y 11$ as well as of all the mentioned parameters of the empirical distribution are calculated and signed automatically by using macroinstructions in MATLAB which are applied and adapted to this case, so that mathematical relations are not necessary, as it is done differently, which is shown in Figure 4.1.

Part of the file analysis1.m for the histogram processing is:

$\mathrm{v}=\mathrm{Y} 11$;

plot(v),grid

keyboard

$\%$ Histogram of the measured value

hist(v),grid

keyboard

$\%$ Frequency of occurrence of the measured value

$\%[\mathrm{fmi}, \mathrm{vm}]=$ hist $(\mathrm{v})$;

$\mathrm{MEV}=\mathrm{mean}(\mathrm{v})$;

$\mathrm{SDE}=\operatorname{std}(\mathrm{v})$;

$\mathrm{N}=$ length $(\mathrm{v})$;

$\mathrm{I}=(\max (\mathrm{v})-\min (\mathrm{v})) / 10$

$\operatorname{MIN}=\min (v)$;

$M A X=\max (v)$;

hist(v),grid

xlabel('... kN');

text(20.7,28.5,['number of sample elements:',num2str(N),]);

text(20.7,27,['minimal value:', num2str(MIN),...'kN']);

text(20.7,25.5,['maximal value:', num2str(MAX),...'kN']); text(20.7,24,['class width:',num2str(I),...'kN']);

keyboard 
A complete histogram of $Y 11$ force is shown in Figure 5.

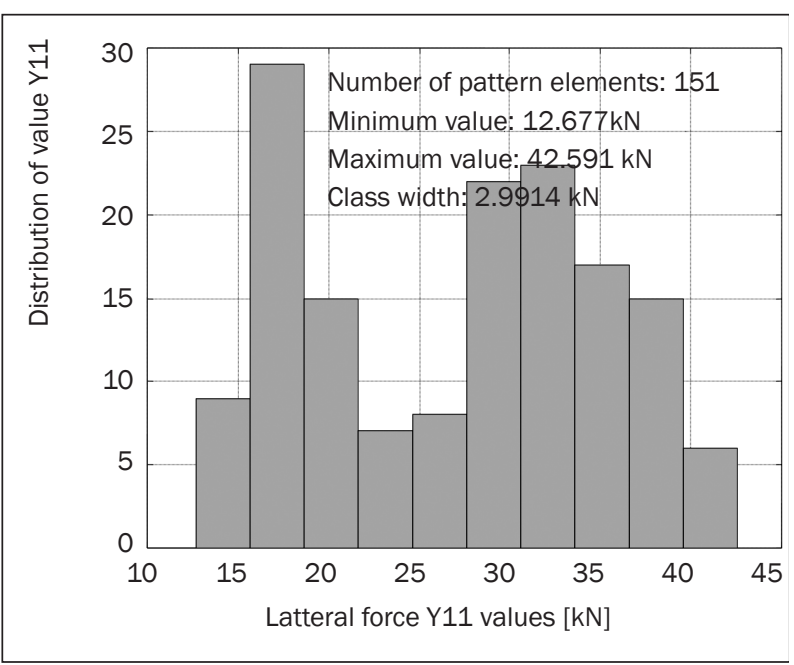

Figure 5 - Empirical distribution of force Y11

\subsection{Normal distributions}

The empirical distribution is obtained from the measurement results and completely corresponds to real data. Based on the given parameters of the empirical distribution for all the measured values, very useful conclusions can be performed regarding the behaviour of the measured vehicle and the rail. The resulting parameters are used in the normal distribution.

Gradually, normal distribution is made out of the empirical distribution, but its characteristics must be defined. Normal distribution has a bell curve of the distribution, which is given by the equation of the normal distribution function. It has its own parameters, specific by its content and labels such as variable $x$, the mean value $(\bar{x})$ and standard deviation $(\sigma)$. The empirical distribution parameters of $N, L, M I N$, and MAX are further used with the normal distribution.

Normal distribution curves occur in two forms; as normal distribution and as normalized normal distribution. In both cases, the design, application and use of these distributions are simply allowed by the MATLAB computer tool.

By replacing the empirical distribution with the theoretical normal distribution, which is allowed by statistical mathematic rules, the possibilities of the exact analyses and assessments are increased regarding the behaviour of the tested facilities and on the basis of the large number of measurement data.

\subsubsection{Normal distribution calculation}

Normal distribution curve, which replaces the empirical distribution along the previous parameters, and along the new ones, is defined:

$f_{t i}=\frac{N . I}{\sigma \cdot \sqrt{2 \cdot \pi}} e^{-\frac{1}{2}\left(\frac{x-\bar{x}}{\sigma}\right)^{2}}$
These are the new parameters:

$x$ - variable

$\bar{x}$.- mean

$\sigma$ - standard deviation

By replacing the empirical distribution (Figure 5) with the normal distribution, the normal distribution force $Y 11$ curve is obtained, according to Figure 6.

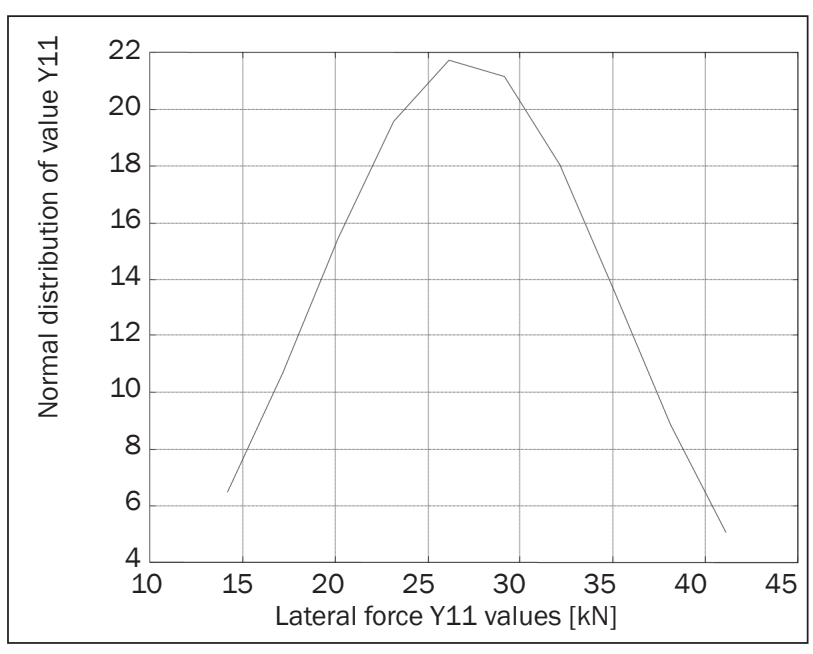

Figure 6 - Normal distribution of force Y11

The following set of commands in the program for the normal distribution is made for the normal distribution curve, but also for the graphic comparison of the empirical and normal distribution of force $Y 11$, as shown in Figure 7:

$\%$ Normal distribution clear $\mathrm{x}$

$\mathrm{x}=(\min (\mathrm{v})+\mathrm{l} / 2): \mathrm{I} \max (\mathrm{v})$

$\mathrm{fti}=\mathrm{N} * \mathrm{l} . /\left(\mathrm{SDE} . *{ }^{*} \operatorname{sqrt}(2 * \mathrm{pi})\right) . * \exp (-1 / 2 *((\mathrm{x}-\mathrm{MEV}) . / \mathrm{SDE}) . \wedge 2) ;$ $\operatorname{plot}\left(\mathrm{x}, \mathrm{fti}, \mathrm{r}^{\prime}\right)$, grid

keyboard

hold

hist(v),grid

hold

keyboard

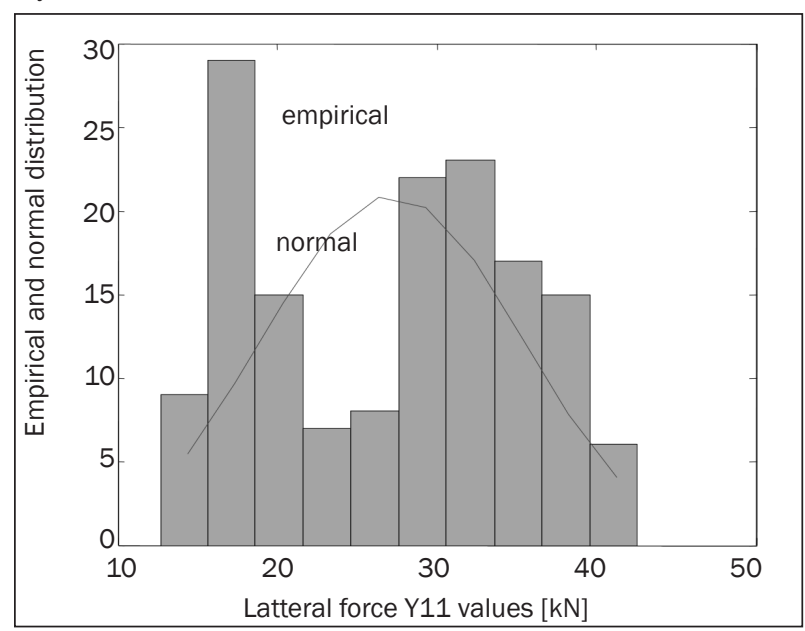

Figure 7 - Graphical comparison of the empirical and normal distribution 


\subsubsection{Normalized normal distribution calculation}

Normalized curve of the normal distribution is the previous curve of the normal distribution reduced to the form and the amount, the area under the bell curve equalling 1 .

New formula for the curve is:

$$
f_{t i 1}=\frac{N . I}{\sigma \cdot \sqrt{2 \cdot \pi}} e^{-\frac{1}{2}\left(\frac{x-\bar{x}}{\sigma}\right)^{2}}
$$

According to the following commands in MATLAB, which are made for the normalized normal distribution, the area for the auxiliary variable $x$ and the step of the auxiliary variable is defined, as well as the commands for drawing curves of the normalized normal distribution function and its parameters.

clear $\mathrm{x}$ fti clg

$\mathrm{x}=(\min (\mathrm{v})-2 * \mathrm{SDE}): 0.01:(\max (\mathrm{v})+2 * \mathrm{SDE})$

$\mathrm{fti}=1 /\left(\mathrm{SDE} .{ }^{*} \operatorname{sqrt}(2 * \mathrm{pi})\right) .{ }^{*} \exp \left(-1 / 2 *((\mathrm{x}-\mathrm{MEV}) . / \mathrm{SDE}) .{ }^{\wedge} 2\right)$;

plot(x,fti),grid

keyboard

text(-5,0.045, ['distribution parameters:']);

text(-5,0.042, ['mean value:',num2str(MEV),...' ‘]);

text(-5,0.039,['standard deviation:',num2str(SDE),...' ']);

keyboard

$\%$ end

The normalized normal distribution curve for the given distribution example for the force $Y 11$ is shown in Figure 8, and the commands for its drawing are already known:

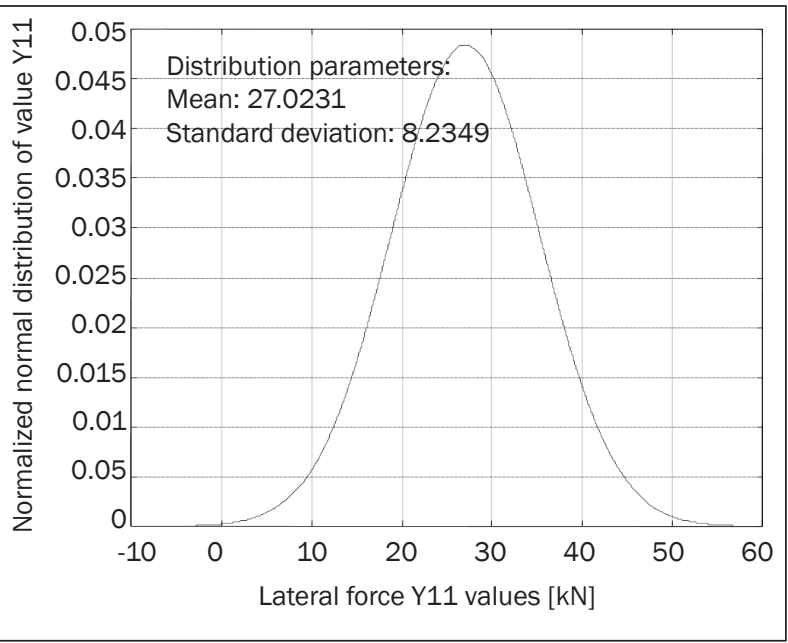

Figure 8 - Normalized normal distribution of force Y11

\subsection{Cumulative distribution calculation and verification of the procedure}

The cumulative distribution is the first application of the normalized normal distribution presented by its curve in Figure 4.2.2. In this example, the calculation of the area under the bell curve of the normalized normal distribution can be seen.

Software which is used for calculating the cumulative distribution is very simple, enabled by MATLAB $\%$ Cumulative distribution $a=\min (v)-2 . * \operatorname{SDE}$ $\mathrm{b}=\max (\mathrm{v})+2 * \mathrm{SDE}$

keyboard

$\mathrm{x}=\mathrm{a}:(\mathrm{b}-\mathrm{a}) / 100: \mathrm{b}$;

keyboard

$\mathrm{P}=$ quad ('ffti1', a, b)

\%keyboard

First, the limits of the distribution function are calculated; they are integrated between the lower $a$ and upper $b$, and surface $P$ is calculated. In the range between the lower and upper limit, the new special variable - vector $x$ is generated by command: $P=$ quad('ffti1', $a, b)$.

Surface $P$ under the normalized curve of the normal distribution is calculated. By definition, this surface must equal 1 , so the process of calculating the surface area is used to verify the authenticity and accuracy of the whole procedure of statistical processing of this step.

The result of calculating the surface under the bell curve which is obtained by normalized normal distribution is excellent: $P=0.9999$.

The developed software used for performing the empirical, normal and cumulative distribution is an essential tool designed for use in other two phases, i.e. mathematically exact evaluation of the maximum values of the measured ones, as well as automatic comparison of the calculated results to the limits according to the UIC CODE 518. The final result is the automatic evaluation and approval of the vehicle and the rail considering safety driving, rail loading and driving comfort compared to the limited values according to UIC CODE 518.

\section{CONCLUSION}

The procedure of the acquisition of measuring dynamic values of forces between the rails and the wheels on the real measurement train and the track has been performed. The conversion of the measured values for the selected railway section in the arc into the matrices and vectors enables numerous exact qualitative and quantitative studies of the dynamic phenomena behaviour.

As an example, the quotient between the lateral force $Y$ and vertical force $Q$ on the first axle wheels of the vehicle are quantitatively and qualitatively shown, which is defined by the UIC CODE 518 as a measure of driving safety.

The possibilities of using MATLAB computer tool are illustrated in fine qualitative and quantitative analysis and the observation of the measured values behaviour, as well as the vehicle-rail system. Furthermore, the commands in the developed software are also given.

The calculation of the empirical, normal and cumulative distribution is provided in detail on an example of the lateral force $Y 11$ as the first phase of software development for the automatic exact statistical 
analysis of the measured data while using MATLAB computer tool. The first phase developed software has been precisely verified and qualified for any further use.

\section{Dr. SC. ZDRAVKO PERAN}

E-mail: zdravko.peran2@si.htnet.hr

Sveučilište u Splitu, Sveučilišni odjel forenzičkih znanosti Ruđera Boškovića 31/IV, 21000 Split, Hrvatska

\section{SAŽETAK}

\section{DINAMIČKE SILE IZMEĐU TRAČNICA I KOTAČA ŽELEZNIČKIH VOZILA}

Postupak akvizicije mjerenih dinamičkih veličina sila između tračnica i kotača na stvarnom mjernom vlaku i kolosijeku. Pretvaranje mjerenih veličina u matrice i vektore omogućava brojna egzaktna kvalitativna i kvantitativna istraživanja ponašanja dinamičkih pojava. Pokazane su mogućnosti up orabe računarskog alata MATLABA. Sve naredbe $u$ softvera dane su i objašnjene. Detaljno se daje izračunavanje empirijske, normalne i kumulativne raspodjele na primjeru jedne bočne sile. Novi softver matematički je egzaktno verificiran i kvalificiran za svu daljnju primjenu. Razvijeni softver je alat za razvoj ostalih dviju faza softvera i to softvera za egzaktnu automatsku procjenu maksimalnih vrijednosti dinamičkih veličina i softvera za automatsko odobravanje vozila i pruge s obzirom na sigurnost vožnje, opterećenje pruge i udobnost vožnje usporedbom s propisanim graničnim vrijednostima iz UIC CODE 518.

\section{KLUUČNE RIJEČI}

mjerni vlak; bočne i okomite sile; UIC CODE 518; sigurnost vožnje; empirijska, normalna i kumulativna raspodjela; verifikacija softvera;

\section{REFERENCES}

[1] UIC, UIC CODE 518. Testing and approval of railway vehicles from the point of view of their dynamic behaviour-Safety-Track fatigue-Ride quality. 3rd ed.; October 2005.

[2] UIC. Testing train ETR-470-ZERO in Croatia. Sync reports, Zagreb; December 1996.

[3] UIC. Measurement data taken by the measurement train on Zagreb-Rijeka railway. Fiat Ferroviaria, Italy; 1996.

[4] Janjanin S, Žerak Lj, Verlić P. The possibility of analyzing the measuring data from the test train by using MATLAB [in Croatian]. Railways 21. Nov 2002;1(1):2030.

[5] Janjanin S, Knaffl I. Mandatory requirements, procedures and criteria used for the introduction of tilting trains [in Croatian]. Railways in theory and practice. Oct 1997;3-4.

[6] Janjanin S, other authors. Dynamic interaction of wheels and rails, set of modeling in science, technology and society [in Croatian]. Zagreb: Hrvatsko društvo za sustave CROSS; 1998.

[7] Janjanin S. To study the simulation of the movement of vehicles in curves [in Croatian]. Zagreb; June 1995. 